\title{
Pulmonary hypertension due to obstruction of the intrapulmonary veins
}

\author{
P. G. I. STOVIN AND M. J. MITCHINSON \\ From Papworth Hospital near Cambridge and the Department of Pathology, Cambridge University
}

Organic obstruction of the pulmonary veins is a rare cause of hypertension in the lesser circulation. Rhomberg in 1891 (quoted by Bürki (1963)) suggested that right ventricular hypertrophy might be due to disturbances in the pulmonary veins, but little note was taken of pulmonary vein lesions producing cor pulmonale until the 1930s when Höra (1934) and Mallory (1937) each described a single case. Others have been described since, and the literature was reviewed by Bürki in 1963.

The present case is presented because of the growing interest in and awareness of the condition, because the diagnosis was suggested by biopsy during life, and because a possible clue to the cause is suggested.

\section{CASE REPORT}

This man, a porter at a butcher's shop, was 41 years old when he died. He usually enjoyed good health but had suffered from a duodenal ulcer which had responded five years previously to simple medical treatment; at the age of 38 he suffered from mumps complicated by orchitis.

His terminal illness lasted 16 months. He complained of exertional dyspnoea and a slight dry cough for which he attended the chest clinic. Nothing abnormal was found other than right ventricular enlargement and congestion of the lungs on radiography. As no improvement occurred and the diagnosis was uncertain, he was admitted six months later, in August 1962, to Papworth Hospital under Dr. M. J. Greenberg. During his 10 days in hospital radiological studies showed a bilateral increase in vascular markings and right interlobar pleural thickening, and the electrocardiogram showed right ventricular strain. There was no evidence of right heart failure. The Kveim test was negative and the Mantoux test was positive at a $1 / 100$ dilution. Haemoglobin and white cell studies, plasma proteins, and urinalysis were all normal. Arterial oxygen saturation was $91 \%$ and lung function tests (Dr. C. Lum) showed a reduced diffusing capacity $\left(D_{L C O} 11\right.$ $\mathrm{ml} . / \mathrm{min} . / \mathrm{mm}$. $\mathrm{Hg}$ ) and compliance was reduced to $120 \mathrm{ml} . / \mathrm{cm}$. water pressure.
By mid-September 1962 increasing exertionalö dyspnoea and nocturnal dyspnoea necessitated his final admission to Papworth Hospital. The jugular venous pressure was raised $2 \mathrm{~cm}$., he showed peripheral cyanosis, and the liver was just palpable 3 There was also a left pleural effusion which was situated chiefly paracardially (Figs. 1 and 2).

The enlarged heart with evidence of failure and noco evidence of valvular, ischaemic or hypertensive disease s led to investigations for cardiomyopathy which included complement fixation and dye test studies foro toxoplasmosis. These tests and their subsequents repetitions were kindly performed by Dr. D. G. Flecko and Dr. G. B. Ludlam. At this initial investigation̋ the dye test titre was $1 / 1024$ and that for the coms plement fixation was $1 / 32$.

During the next one and three-quarter months hêे required 11 aspirations of the recurrent left pleura? effusion. In all, 16.25 litres were aspirated. This fluid was predominantly lymphocytic but did show. an occasional mild eosinophilia. Repeated attempts failed to grow toxoplasma from the fluid. A pleura biopsy at this time yielded fibrinous exudate with a single collection of unidentified round bodies whicho were not toxoplasma (Fig. 3).

Treatment with sulphatriad and pyrimethamines (Daraprim) was instituted on the assumption that the raised toxoplasma antibody titres indicated a recento infection. This treatment had to be discontinued after? three weeks because of thrombocytopenia $(16,000 / D$ $\mathrm{mm}^{3}$ ) and granulopenia (59\% of 4,500 white cells $\left.\mathrm{mm} .{ }^{3}\right)$. Recovery from this blood dyscrasia soorn occurred after withdrawal of the drugs.

By January 1963 a tricuspid pansystolic murmur was heard for the first time. A cardiac catheter wast passed which revealed an elevated pulmonary arteryo pressure of $75 / 25 \mathrm{~mm}$. Hg with a mean of $40 \mathrm{~mm}_{0}$ $\mathrm{Hg}$; the wedge pressure was elevated at $23 / 15 \mathrm{~mm}$ ? $\mathrm{Hg}$ with a mean of $18 \mathrm{~mm}$. $\mathrm{Hg}$ which rose to 29 on exercise. The pulmonary vascular resistance was moderately raised to 4.0 units. Arterial oxygen satura $-\frac{0}{0}$ tion was $86 \%$ at rest and rose to $98 \%$ after breathing oxygen for 10 minutes. There was no evidence of valve stenosis or any intracardiac shunts.

Lung function studies a week after the cardiaco catheterization re-affirmed the increased lung stiffness recorded at the earlier study. 


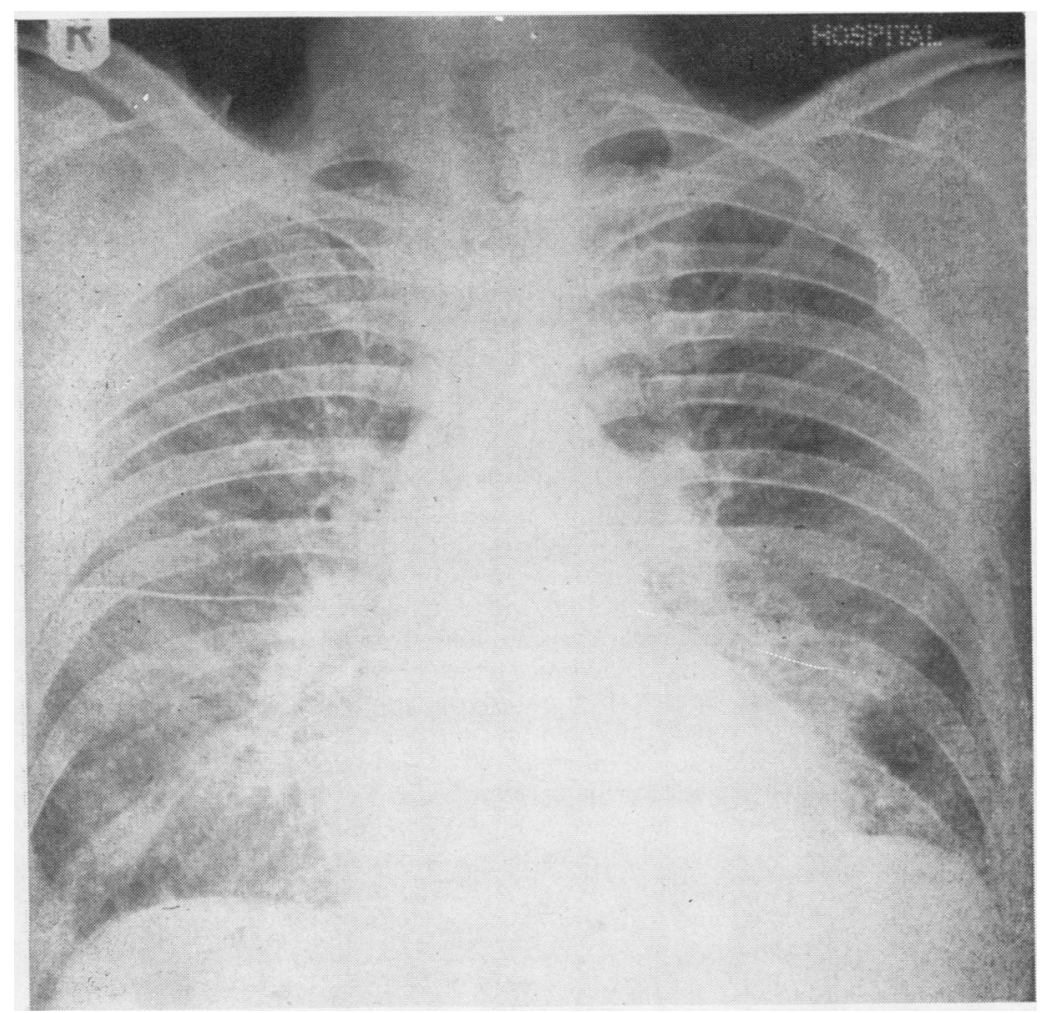

FIG. 1. Chest radiograph. P.A. in upright position.

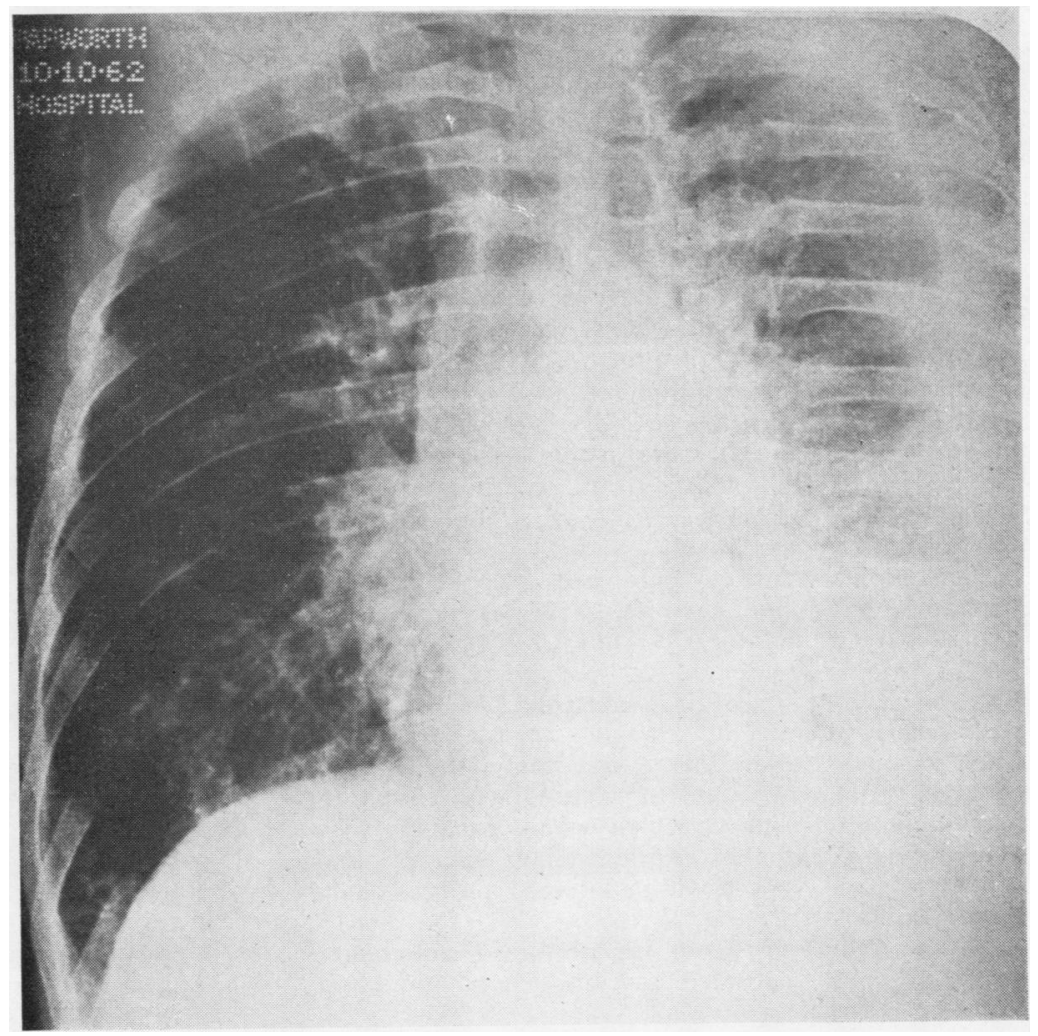

FIG. 2. Chest radiograph. P.A. in left lateral decubitus, showing shift of the paracardial effusion. 


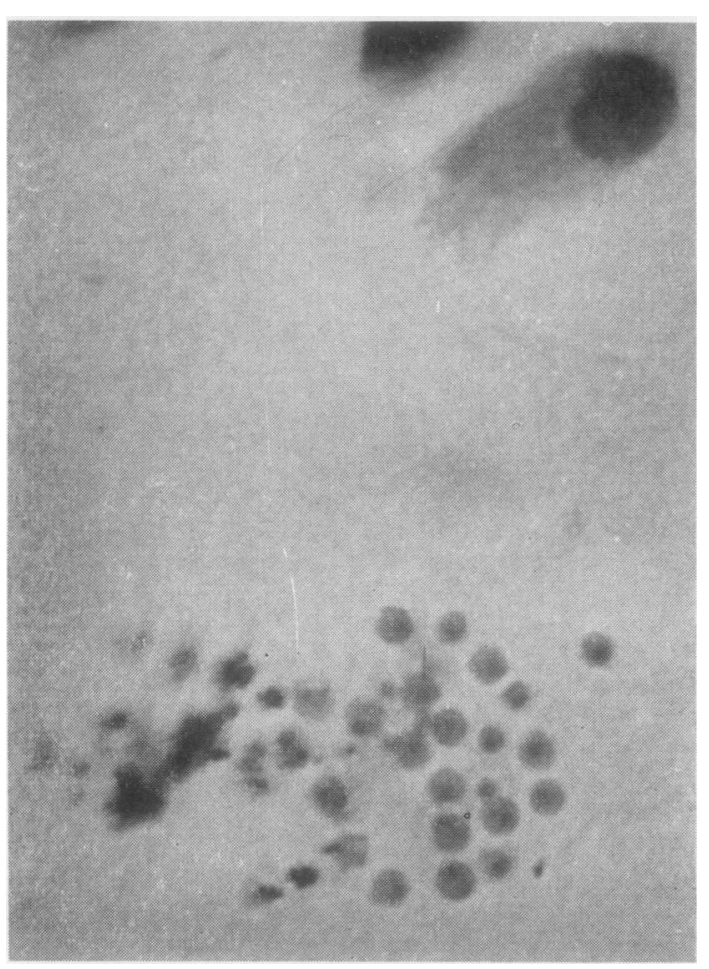

FIG. 3. The group of round bodies seen in the fibrinous pleural exudate. H. and E., $\times 1,700$.

Because of the persisting uncertainty about the lesions present in this patient thoracotomy was advised and performed by Mr. C. Parish on 24 January 1963. The lung felt tougher than normal but was of normal colour and aeration. The left parietal pleura and pleuro-pericardial membrane was thickened. Direct recordings were made of pressure in the main pulmonary artery which was raised to $75 / 35 \mathrm{~mm}$. $\mathrm{Hg}$, while the pressure in the left ventricle was normal at $85 \mathrm{~mm} . \mathrm{Hg}$ and the pressure in the left superior pulmonary vein both inside and outside the pericardium was not elevated, being only $6 \mathrm{~mm}$. Hg. A biopsy was taken from the lingula.

This biopsy showed organized and recanalized thrombus in a pulmonary vein (Fig. 4) and medial hypertrophy in pulmonary arterioles (Fig. 5). There was a moderate degree of paraseptal interstitial fibrosis and clumps of iron-containing macrophages were seen in the alveoli.

Eleven days after the thoracotomy the patient suffered from an episode of fainting with dyspnoea and radiological changes which were compatible with a pulmonary embolus. Anticoagulant therapy and prednisone were started and maintained until his death four months later.

As the symptoms from his presumed pulmonary embolus rapidly subsided and his general condition seemed fairly static and the biopsy showed onl올 established lesions he was discharged home on 2. March. Just before his discharge repeat lung functiow tests showed no appreciable change from the previoug tests.

Early in the morning of 11 June 1963 he died at his home. Permission for a necropsy was obtained and this was performed at Addenbrooke's Hospital. Apart from $500 \mathrm{ml}$. of ascites, congestion of the abdominaw viscera, and fibrosis of the right testis, the majos pathological lesions were confined to the thoraci $\vec{\alpha}$ viscera. The heart weighed $547 \mathrm{~g}$., and this increased in weight was due to hypertrophy of the right ventricle which was dilated, the wall measuring $8 \mathrm{~mm}$. in thickness at the pulmonary conus. The right atriuns and tricuspid valve ring were dilated although the tricuspid valve leaflets were normal. The left ventricle was of flabbier consistency than the right and was dilated but not hypertrophied. The left atrium and main pulmonary veins were normal. The valves were also all normal. The coronary arteries were patent. and normally distributed.

There were bilateral serous pleural effusions eacks of $200 \mathrm{ml}$. with some tough fibrous adhesions. The left lung weighed $857 \mathrm{~g}$. and on slicing was of toug and rubbery consistency with prominent pulmonary

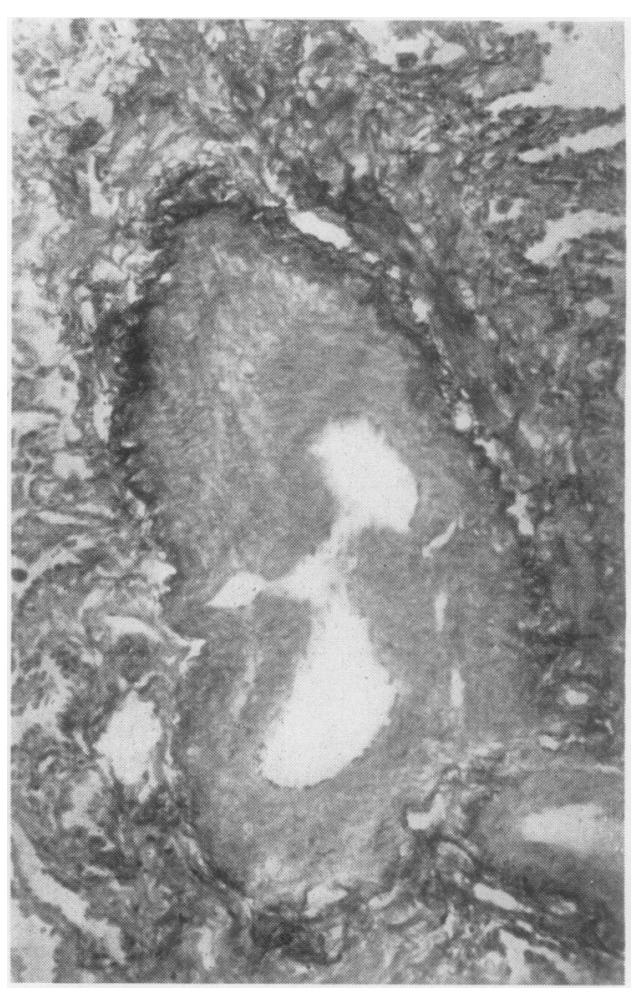

FIG. 4. Lingula biopsy. Organized thrombus in a pulmonar vein. Elastic, van Gieson, $\times 100$. 


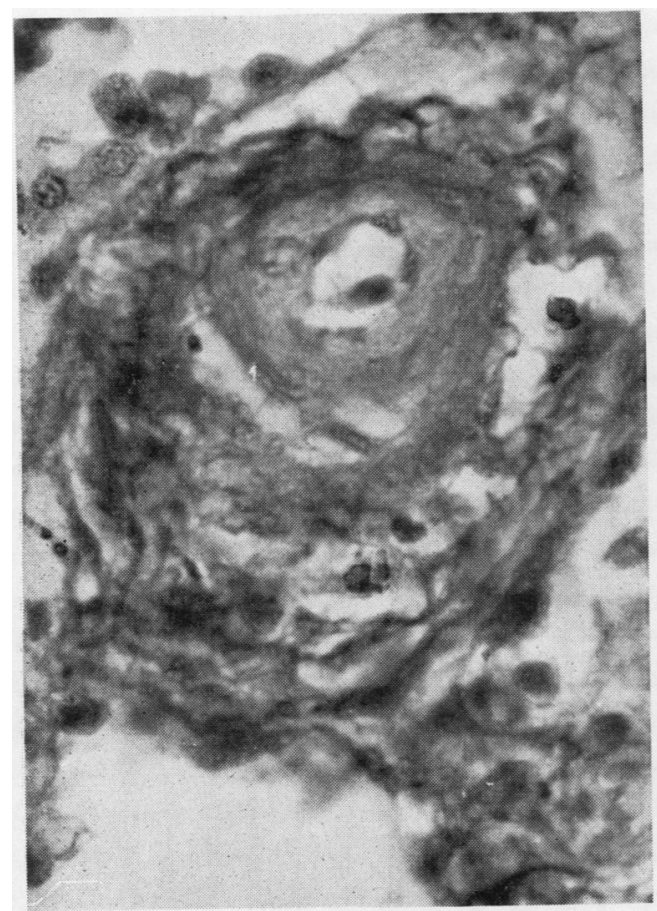

FIG. 5. Lingula biopsy. Medial hypertrophy of a pulmonary arteriole. Elastic, van Gieson, $\times 715$.

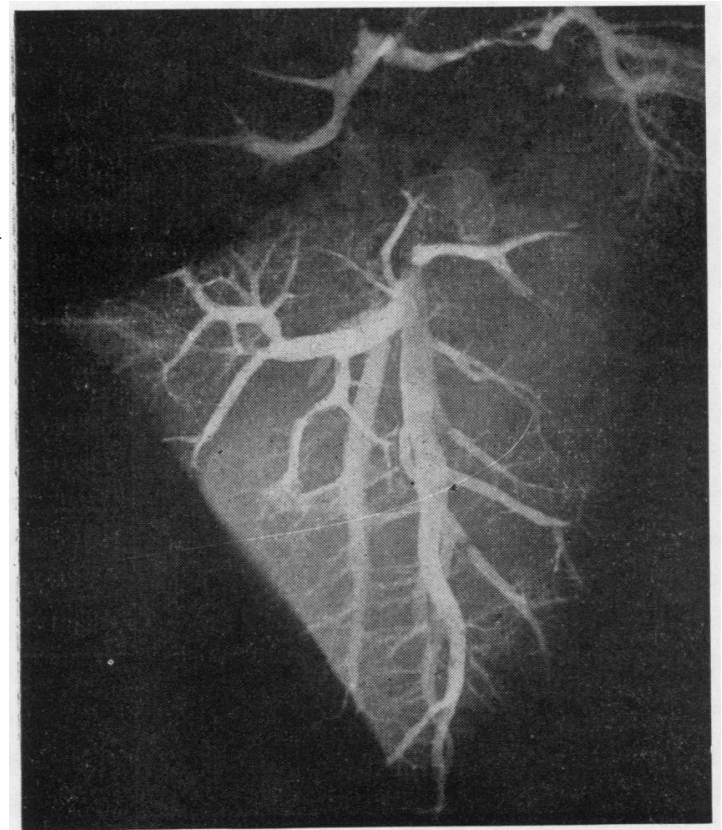

FIG. 6. Necropsy specimen. Right lower lobar phlebogram showing occlusion of several subsegmental veins.

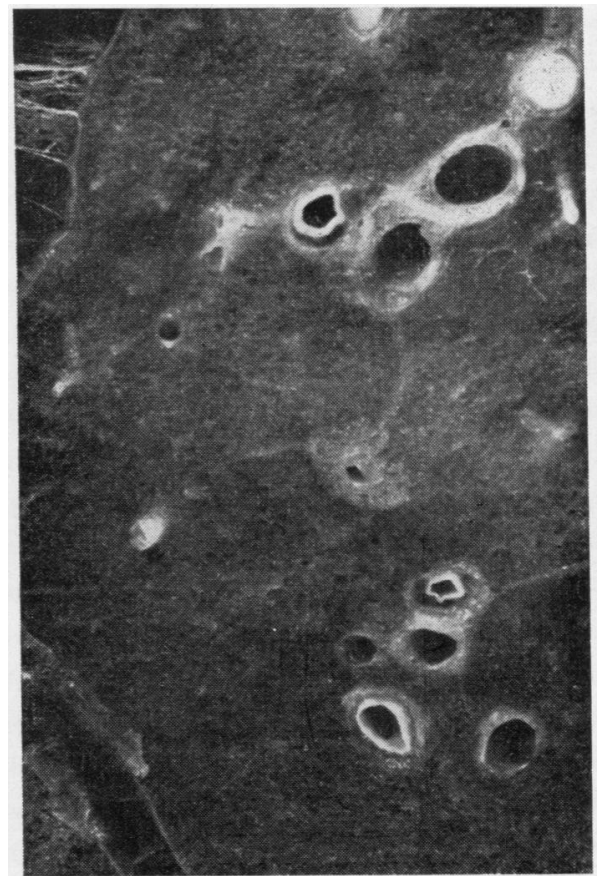

FIG. 7. Necropsy specimen. Right upper lobe. Thickened adventitia and partial occlusion of the lumen of the vein in the centre of the picture.

arteries on the cut surface. The right lung, weighing $997 \mathrm{~g}$., was retained for injection of the pulmonary vein to the lower lobe and the pulmonary artery to the upper lobe after which the lung was fixed by the Heard (1960) technique. Unfortunately, the injection studies were not entirely satisfactory as it was not technically possible to ensure maximum permeation of the barium sulphate-gelatine injection mass; however, there were obvious occlusive lesions in the veins (Fig. 6).

On serial slicing of the inflated fixed right lung it was evident that several branches of both the upper and lower pulmonary veins (Fig. 7) were obliterated by organized thrombus with an increase in thickness of the perivenous connective tissue, and even macroscopically visible anastomoses with the bronchial veins could be made out by careful dissection. There were lobular areas of what appeared to be old infarcts which were especially prevalent along the vertebral border of the lower lobe.

Microscopically the lungs showed the major pathological changes. Several of the larger pulmonary veins were extensively occluded by organized and recanalized thrombus (Fig. 8) or by a marked concentric intimal thickening made up of material which stained a pale red with van Gieson, hardly at all for reticulin or with the periodic-acid-Schiff-alcian blue sequence, and only a faint blue with Lendrum's MSB method (Lendrum, Fraser, Slidders, and Henderson, 1962). 


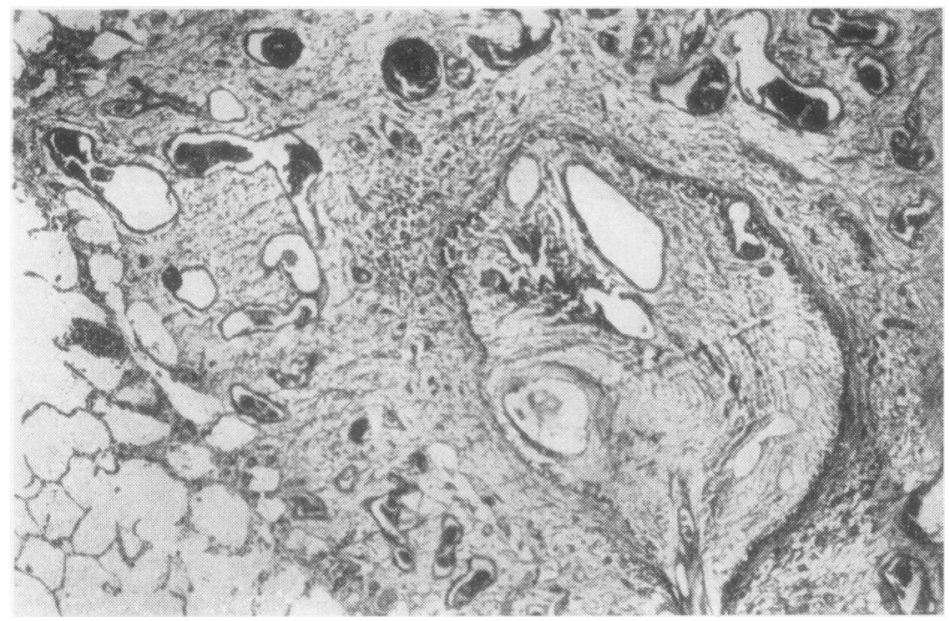

FIG. 8. Necropsy specimen. Organized recanalized thrombotic occlusion of vein with dilated anastomotic vessel $\overrightarrow{0}$ in the adventitia. Elastic, van Gieson,

$\times 27$.

FIG. 9. Necropsy specimen. Marked intimal swelling of small pulmonary vein. Elastic, van Gieson, $\times 85$.
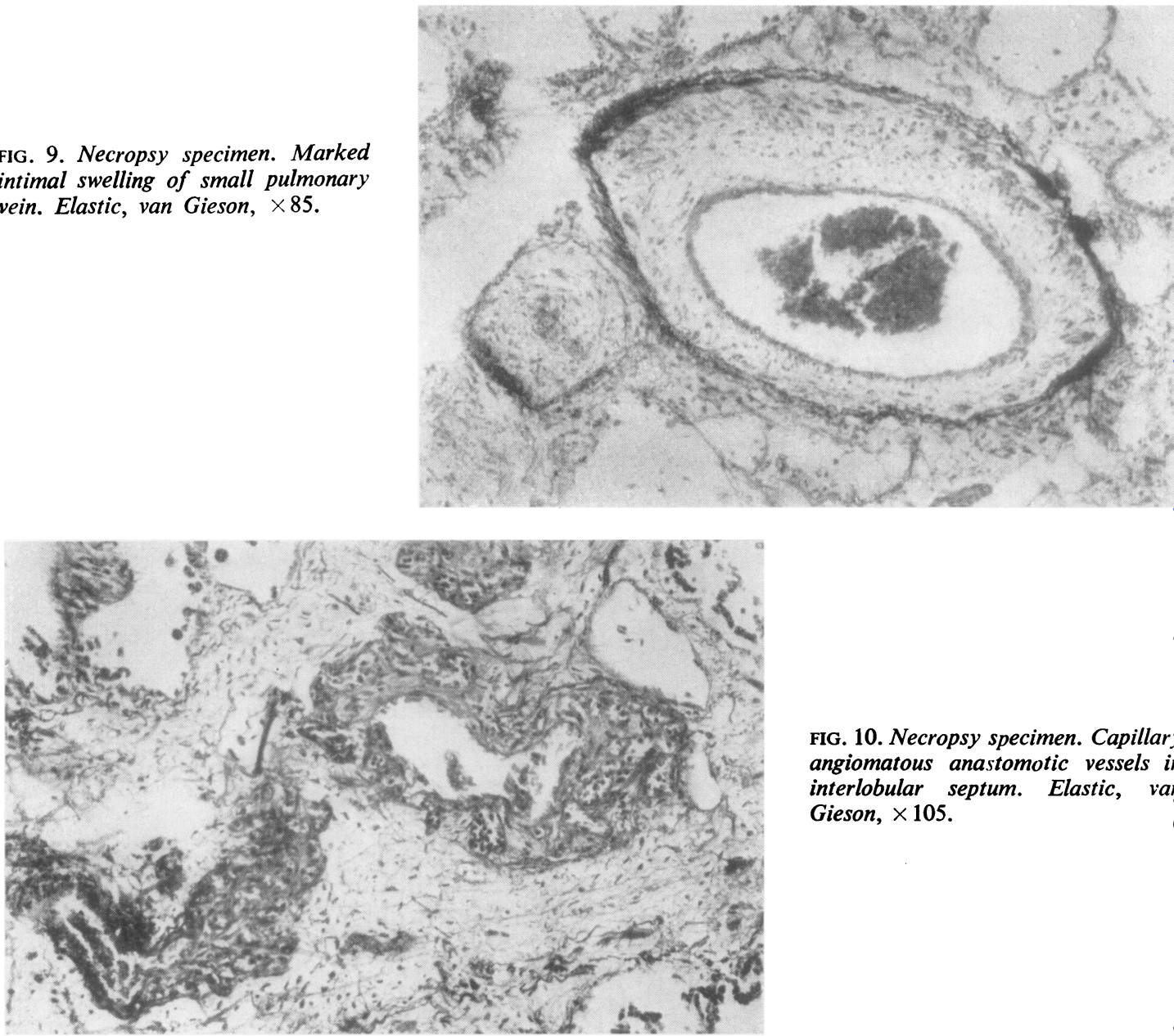

FIG. 10. Necropsy specimen. Capillary angiomatous anastomotic vessels in interlobular septum. Elastic, varo Gieson, $\times 105$. 
Similar oedematous, mainly concentric intimal swelling was seen considerably to narrow or virtually obliterate many of the smaller veins (Fig. 9) and venules. The media of the veins of all calibres was normal but the adventitia was thickened, more by oedema than by an increase of fibrous connective tissue. In this thickened adventitia were numerous dilated thin-walled vessels which were larger about the larger veins and smaller, appearing as capillary angiomata, in the interlobular septa (Fig. 10). The alveoli were only patchily engorged, and in areas where the larger veins were obstructed the alveolar walls were thickened by a loose, sparsely cellular, interstitial fibrosis in places accompanied by a cuboidal cell lining to the alveoli. In these more severely affected areas, the small arteries and arterioles showed a combination of iron impregnation, fibrinous vasculosis (Lendrum, 1955), and medial hypertrophy without intimal proliferation. In the areas without obstruction to the larger veins the arteries and arterioles showed only medial hypertrophy. Some of the larger elastic pulmonary arteries showed intimal fibro-elastic thickening. The iron and fibrin impregnation of the walls of some of the pulmonary arterioles was interpreted as a response to intraalveolar haemorrhage and pulmonary hypertension, both resulting from pulmonary venous obstruction. The dilated vessels and the leashes of capillaries in the adventitia of the veins were interpreted as venous anastomotic channels.

The bronchial arteries showed no abnormality and the pleural veins were dilated. Bronchial and septal lymphatic vessels were dilated.

The alveoli contained a moderate number of siderocytes which seemed to be fewer than in the biopsy.

In sections of other organs there was little of note other than congestion. The right ventricle was hypertrophied and the right testis was fibrotic and contained some haemosiderin, suggesting an infarct.

\section{DISCUSSION}

Although the functional effect on the lungs and right side of the heart may be the same whatever the site of the venous obstruction, consideration of the site of the obstruction may help to distinguish different clinical and aetiological groups.

Severe venous intimal fibrosis is sometimes seen (Heath and Edwards, 1959) in association with the high pulmonary blood flow that occurs with atrial septal defects. Pulmonary vascular thromboses are also seen most commonly in impaired pulmonary blood flow, especially when this is associated with polycythaemia as in pulmonary stenosis or Fallot's tetralogy (Harris and Heath, 1962). Such congenital cardiac anomalies were absent in the present case.
Congenital stenosis of the origins of the pulmonary veins, as described by Lucas, Woolfrey, Anderson, Lester, and Edwards (1962), is also excluded by the operative and necropsy findings.

Likewise, acquired stenosis of the main pulmonary veins due to the condition called mediastinal granuloma (Edwards and Burchell, 1951) is excluded in the present case. In Edwards and Burchell's case, besides the obstruction to the main veins, there was also 'tremendous fibrous non-intimal thickening' of some vessels in the hung substance; these vessels were thought to be veins. Similar changes, but occurring in the intima, were observed by Heath and Edwards (1959) in their case 13. These authors found no evidence of venous thromboses ; however, Evans (1959), in describing a case of strangulation of the main pulmonary veins by a mediastinal granuloma, reported frequent pulmonary venous thromboses. Andrews (1957), in reporting another case of mediastinal granuloma, commented on the pulmonary arterial hypertensive changes and on the commencing interstitial fibrosis but made no observations on the pulmonary veins.

Thus it seems that organic obstruction of the main pulmonary veins is not usually accompanied by thrombotic lesions in the medium-sized or smaller veins even though pulmonary arterial hypertension is present. The veins are not normal. being often affected by fibrous thickening of the intima, hypertrophy of the medial muscle, and by an increased prominence of the elastic lamellae. These changes in the veins appear to be an accentuation of the changes seen in physiological obstruction to the pulmonary venous return as in mitral stenosis. The changes in the pulmonary blood vessels in co-existing pulmonary arterial and venous hypertension have been reviewed by Heath, Cox, and Harris-Jones (1957), who discussed the varying degrees of difference in arterial, arteriolar, capillary, and venous intimal and medial changes and related them to the findings at cardiac catheterization. In their case of Fiedler's myocarditis the venous hypertensive lesions were more in evidence than they would have expected from a comparably hypertensive mitral stenosis.

In the present case a myocarditis seems to be excluded by the normal pressure recorded at thoracotomy in the main pulmonary vein and by the absence at post-mortem examination of any microscopical myocardial lesions.

Lesions of the pulmonary venous intima in the absence of cardiac abnormalities are very rare. Two histological types of venous intimal lesion are, however, on record: intimal swelling and thrombosis. In the present case the medium- 
sized veins contained recanalized and organized thrombus and the smaller veins showed intimal thickening by sparsely cellular oedematous collagenous tissue. In the case reported by Crane and Grimes (1960) the large, medium, and smaller pulmonary veins were affected by a collagenous intimal thickening which reduced their lumen to a slit or crescent. The medium-sized and small veins were affected more severely than the larger.

In other recorded cases the small veins and venules were the seat of an intimal thickening (Mallory, 1937 ; Könn, 1956 ; Brewer and Humphreys, 1960 ; Bürki, 1963). In these, the thickening was of a collagenous or oedematous fibroblastic nature. In contrast, the description and illustrations given by Höra (1934) suggest that the obstruction in the small veins and venules was organizing thrombi. In Manzini's (1947) case there was a mixture of lesions, namely a poorly cellular collagenous intimal thickening affecting the arteries and small veins, and organized and recanalized thrombosis of the larger pulmonary veins.

The pulmonary arterioles in all these cases of pulmonary venous and venular sclerosis discussed above have been affected by intimal proliferation and medial hypertrophy. The changes in the veins and arteries have approximately paralleled each other and have been accompanied by interstitial thickening of the alveolar walls, congestion of the alveolar capillaries, haemosiderosis of the alveolar macrophages, and sometimes iron impregnation of elastic fibres. All these changes can be explained if the obstruction of the pulmonary veins is the primary event.

An initial febrile episode has been recorded by Brewer and Humphreys (1960) and by Crane and Grimes (1960) which might indicate an inflammatory basis for the venous sclerosis. In the present case this possibility is also raised because, although the patient was apyrexial, he did have serological tests suggestive of toxoplasmic infection, the titres of which progressively fell as shown in the Table. However, medial fibrosis of the veins has been recorded only by Crane and

TAB LE

RECIPROCAL OF TITRES TO TOXOPLASMA

\begin{tabular}{c|c|c}
\hline Date & Dye Test & $\begin{array}{c}\text { Complement } \\
\text { Fixation }\end{array}$ \\
\hline 26 September 1962 & 1,024 & 32 \\
11 October 1962 & 256 & 4 \\
19 November 1962 & 256 & 4 \\
10 January 1963 & 256 & 8 \\
15 February 1963 & 256 & $<4$ \\
18 April 1963 & 128 & $<4$ \\
\hline
\end{tabular}

Grimes (1960), and these authors did not suggest $\frac{7}{0}$ that this fibrosis represented the residue of $a$ 듬 primary phlebitis.

In both Manzini's (1947) and Könn's (1956) cases there was associated renal disease: pyelitis and renal calculus in the former, and chronic ${ }^{\infty}$ glomerulonephritis in the latter. Könn also quotes $\vec{\circ}$ a case described by Probst in 1955 of pulmonary $\overrightarrow{\vec{H}}$ haemosiderosis with obstruction of the pulmonary veins and glomerulonephritis. In view of the $\overrightarrow{\overrightarrow{2}}$ haemosiderosis of the lungs in these cases it would be tempting to speculate that Könn's and $\bigcirc$ Probst's cases indicate a relationship to Good-? pasture's (1919) syndrome. Neither Goodpasture $\vec{\circ}$ nor other subsequent writers (Rusby and Wilson, 을 $1960)$ have described pulmonary venous lesions in cases of lung purpura with nephritis.

Manzini's (1947) case was associated with generalized thrombophlebitis. Although no $\frac{\widehat{\partial}}{\partial}$ systemic venous lesions were present in the case $\vec{\bullet}$ described by Bürki (1963), this author thought on $/ \mathrm{f}$ histological grounds that the lesions in the pulmonary veins had similarities to the hepatic venous lesions in the Budd-Chiari syndrome. Moschcowitz (1962) noted an association between $\overline{0}$ intimal sclerosis in the pulmonary and portal veins which he related to the porto-pulmonary $\stackrel{\mathbb{2}}{2}$ venous anastomoses and to the effect of congestive $\overrightarrow{\vec{O}}$ cardiac failure on the intrahepatic circulation. 3 The changes, observed by Moschcowitz, were rela-? tively mild and were not the stenotic plaques? which Bürki was considering.

The significance of the toxoplasmic serologicalo test results requires additional comment. They $\underset{x}{0}$ have been mentioned already in relation to the evidence for an inflammatory cause for the pulmonary phlebothrombosis. Although the actualo titres are high, they are not elevated to such a degree as to be diagnostic. Ludlam and Beattie 의 (1963) suggested that a dye test titre of 1/1024D with a clear change of titre might be significant, and they suggested that an eightfold fall in N titre could be regarded as a clear change outside the range of an anamnestic response. These $\mathcal{O}$ criteria are more stringent than those given by Beverley (1960), who accepted a 1/256 dye test? titre and a $1 / 8$ complement fixation titre as fairlyo certain indications of infection. The changes in $\overline{\mathbb{}}$ titre in both the dye and complement fixation tests? in the present case were just eightfold and are $\square$ therefore suggestive of a toxoplasmic infection? occurring about the same time as the onset of $\stackrel{\mathbb{Q}}{\mathscr{Q}}$ symptoms.

Pulmonary involvement by toxoplasma iso recorded both experimentally and in humans and appears to be a terminal event in a fulminatingo 
septicaemic form of the disease (Hemsath and Pinkerton, 1956; Beverley, 1960 ; Perrin-Fayolle and Garin, 1960). Sero-fibrinous pleural exudation is known to occur in congenital toxoplasmosis (Beverley, 1960). Beverley, in a personal communication, did not regard the bodies (Fig. 3) seen in the pleural exudate of this patient as the rounded form of toxoplasma which is sometimes seen when the organism is encountering adverse conditions. Pleural involvement in adult toxoplasmosis appears to be distinctly unusual but was noted by Ludlam and Beattie (1963) in two of the nine cases they reported in which the serological investigations suggested the possibility of pulmonary toxoplasmic disease without fulminating toxoplasmic septicaemia. Perrin-Fayolle and Garin (1960) recorded a possible clinical case of chronic miliary pulmonary toxoplasmosis which had no pleural involvement.

Venous lesions are not recognized as a result of toxoplasmic infection. There was no disruption of the elastica nor fibrosis of the media of the veins to indicate that the observed venous lesions were the result of an antecedent phlebitis. It is possible that the venous lesions were a sequel to the altered haemodynamics produced by the interstitial type of inflammation seen in pulmonary toxoplasmic infection.

In conclusion it must be said that although the evidence for a toxoplasmic aetiology for the pulmonary phlebothrombosis is tenuous, such an aetiology cannot be excluded so that in similar cases in the future studies for this organism are indicated.

\section{SUMMARY}

The case of a 41-year-old man who died from pulmonary hypertension is presented. Lung biopsy in life and necropsy studies showed that the pulmonary hypertension was due to obstruction of the small and medium-sized pulmonary veins by organized thrombus and an oedematous intimal swelling. There was serological evidence of a coincidental toxoplasmic infection, the significance of which is discussed.

We wish to thank Dr. M. J. Greenberg for permission to report this patient, and Dr. G. A. Gresham for permission to publish the necropsy observations. Our thanks are also due to Dr. C. Lum, Dr. D. G. Fleck, Dr. G. B. Ludlam, Dr. H. A. Fleming, and Mr. C. Parish for their reports on various aspects of the patient's disease. We wish to thank Mr. E. Groves and Mr. A. Matthews for the photographs and Mrs. S. Oxbury for secretarial assistance.

This work was helped by a grant from the East Anglian Regional Hospital Board Research Funds.

\section{BIBLIOGRAPHY}

Andrews, E. C., Jr. (1957). Five cases of an undescribed form of pulmonary interstitial fibrosis caused by obstruction of the pulmonary veins. Bull. Johns Hopk. Hosp., 100, 28.

Beverley, J. K. A. (1960). The laboratory diagnosis of toxoplasmosis. In Recent Advances in Clinical Pathology. Ed. S. C. Dyke. P. 38. Churchill, London.

Brewer, D. B., and Humphreys, D. R. (1960). Primary pulmonary hypertension with obstructive venous lesions. Brit. Heart J., $22,445$.

Bürki, K. (1963). Eine primäre isolierte obliterierende Pulmonalvenenveränderung als Ursache eines chronischen Cor pulmonale. Arch. Kreisl.-Forsch., 40, 35.

Crane, J. T., and Grimes, O. F. (1960). Isolated pulmonary venous sclerosis: A cause of cor pulmonale. J. thorac. cardiovasc. Surg., 40, 410 .

Edwards, J. E., and Burchell, H. B. (1951). Multilobar pulmonary, venous obstruction with pulmonary hypertension. "Protective", arterial lesions in the involved lobes. Arch. intern. Med., 87, 372.

Evans, W. (1959). The less common forms of pulmonary hypertension. Brit. Heart J., 21, 197.

Goodpasture, E. W.'(1919). The significance of certain pulmonary lesions in relation to the etiology of influenza. Amer.J.med. Sci., $158,863$.

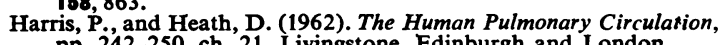
pp. 242-250, ch. 21 . Livingstone, Edinburgh and London.

Heard, B. E. (1960). Pathology of pulmonary emphysema. Methods of study. Amer. Rev. resp. Dis., 82, 792.

Heath, D., Cox, E. V., and Harris-Jones, J. N. (1957). The clinicopathological syndrome produced by co-existing pulmonary arterial and venous hypertension. Thorax, 12, 321 .

and Edwards, J. E. (1959). Histological changes in the lung in diseases associated with pulmonary venous hypertension. Brit.J. Dis. Chest, 53,8 .

Hemsath, F. A., and Pinkerton, H. (1956). Disseminated cytomegalic inclusion disease and disseminated toxoplasmosis in an adult with myeloid metaplasia. Amer. J. clin. Path., 26, 36.

Höra, J. (1934). Zur Histologie der klinischen "Primären Pulmonalsklerose". Frankfurt. Z. Path., 47, 100.

Könn, G. (1956). Die pathologische Morphologie der Lungengefässe bei chronischem Cor pulmonale. Beitr. path. Anat., 116, 273.

Lendrum, A. C. (1955). Fibrinous vasculosis. J. clin. Path., 8, 180. Fraser, D. S., Slidders, W., Henderson, R. (1962). Studies on the character and staining of fibrin. Ibid., 15, 401 .

Lucas, R. V., Woolfrey, B. F., Anderson, R. C., Lester, R. G., and Edwards, J. E. (1962). Atresia of the common pulmonary vein. Pediatrics, 29, 729.

Ludlam, G. B., and Beattie, C. P. (1963). Pulmonary toxoplasmosis.

Lancet, 2, 1136.
Mallory, T. B. (1937), Case records of the Massachusetts General Hospital, Case 23511. New Engl. J. Med., 217, 1045.

Manzini, C. (1947). Endophlebitis obliterans universalis, vorwiegend der Lungenvenen, mit konsekutivem Cor pulmonale. Schweiz. $Z$. Path., 10, 309.

Moschcowitz, E. (1962). Studies in phlebosclerosis IV. Phlebosclerosis of the pulmonary veins. Amer. J. Cardiol., 10, 836.

Perrin-Fayolle, M., and Garin, J. P. (1960). La toxoplasmose pulmonaire. Faits expérimentaux et cliniques. Presse méd., 68, 1994.

Rusby, N. L., and Wilson, C. (1960). Lung purpura with nephritis. Quart. J. Med., 29, 501. 